\section{Serum and salivary cortisol in the diagnosis of adrenal insufficiency and as a predictor of the outcome in patients with severe sepsis}

\author{
Avaliação do cortisol sérico e salivar no diagnóstico \\ da insuficiência adrenal e como parâmetro preditor \\ da evolução de pacientes com sepse grave
}

Rômulo Carvalho Vaz de Mello', Eduardo F. Sad², Bertha Coelho

Andrade', Suzane Pretti Figueiredo Neves', Silvana Maria Elói Santos', Marta Maria S. Sarquis ${ }^{3}$, Paul E. Marik ${ }^{4}$, Eduardo Pimentel Dias ${ }^{5}$
${ }^{1}$ Complementary Propedeutics, Universidade Federal de Minas Gerais (UFMG), Belo Horizonte, MG, Brazil ${ }^{2}$ Internal Medicine, Hospital Felício Rocho, Belo Horizonte, MG, Brazil ${ }^{3}$ Internal Medicine, UFMG, Belo Horizonte, MG, Brazil; Instituto Felice Rosso de Pesquisa e Educação Continuada (IFERPEC), Hospital Felício Rocho, Belo Horizonte, MG, Brazil

${ }^{4}$ Division of Pulmonary and Critical Care Medicine, Thomas Jefferson University, Philadelphia, PA, USA ${ }^{5}$ Complementary Propedeutics, UFMG; IFERPEC, Hospital Felício Rocho, Belo Horizonte, MG, Brazil

Correspondence to: Rômulo Carvalho Vaz de Mello Propedêutica Complementar, Universidade Federal de Minas Gerais Av. Prof. Alfredo Balena, 190/403 30130-100 - Belo Horizonte, MG, Brazil romulomello@hotmail.com

Received on 14/Feb/2011 Accepted on 15/Sept/2011
1,64 , de $80 \%$, com significância estatística, quando comparado com os pacientes com níveis mais baixos $(Z=2,38$ e $p<0,05)$. Conclusões: Cortisol salivar em pacientes críticos parece ser um melhor marcador da atividade glicocorticoide que o cortisol sérico total. Arq Bras Endocrinol Metab. 2011;55(7):455-9

\section{Descritores}

Cortisol salivar; cortisol sérico total; CIRCl; albumina; sepse grave; pacientes em pós-operatório 


\section{INTRODUCTION}

Cevere illness and stress require an adaptive response $\checkmark$ mediated by activation of the hypothalamic pituitary adrenal axis (HPA) and of the sympathoadrenal system, which includes the sympathetic nervous system and the adrenal medulla (1).

Critical illness-related corticosteroid insufficiency (CIRCI), formerly called relative adrenal insufficiency, may be defined as inadequate corticosteroid activity for illness severity (2). CIRCI may occur because of inadequate response of the HPA axis to stress, or due to impaired activity of the nuclear glucocorticoid receptor complex (2).

Reported prevalence of CIRCI varies widely depending on the population studied and on the diagnostic criteria used, but it is more common in patients with septic shock (3-8). The correct identification of CIRCI and its prompt treatment have implications in the outcome of critically ill patients $(6,9,10)$.

Currently, there is no consensus on the laboratory diagnosis of CIRCI. At this time, CIRCI is best diagnosed by random total cortisol $<10.0 \mu \mathrm{g} / \mathrm{dL}$ or its increment after corticotrophin (1-24 ACTH [adrenocorticotrophic hormone]) administration $<9.0 \mu \mathrm{g} /$ $\mathrm{dL}(2,3)$. Many studies have described limitations of serum total cortisol in critically ill patients, especially in those with low albumin levels (less than $2.5 \mathrm{~g} / \mathrm{dL}$ ). This has been attributed to low transcortin levels in this population, since it has been shown that disproportionately larger increases in free, as compared with total cortisol, occur when the binding capacity of transcortin is exceeded (11-13).

In critically ill patients, free serum cortisol is markedly increased, but this is not clearly discernible when only serum total cortisol is measured (12-14). The high cost and low availability of equilibrium dialysis followed by radioimmunoassay to determine free serum cortisol limit its use in routine clinical care. It is well-known that salivary cortisol is in equilibrium and correlates with the free fraction of this hormone in circulation $(13,15)$. Salivary cortisol measurements are frequently used in the evaluation of patients with suspect Cushing's syndrome and has become a commercially available method (16-18).

The aim of this study was to compare the increment in salivary cortisol with that of serum total cortisol in Intensive Care Unit (ICU) patients with severe sepsis in a normal population. In addition, we compared cor- tisol levels in patients with sepsis and in postoperative patients.

\section{MATERIALS AND METHODS}

\section{Patient population and study design}

This study was approved by the Ethics Committee of Hospital Felício Rocho. An informed consent form was signed by all patients or, if unable to sign, the member of the family responsible for them, as well as all control subjects. From March to September of 2006, 66 individuals were enrolled in the study. Total serum and salivary cortisol were collected at the time of diagnosis in 27 patients with severe sepsis, before any treatment decisions concerning corticotherapy. Diagnosis of severe sepsis was based on the criteria established by the American College of Chest Physicians and the Society of Critical Care Medicine (19). Twenty postoperative, hemodynamically stable patients that were not receiving mechanical ventilatory support or vasoactive drugs were also selected. Samples of blood and saliva were collected in the morning of the first day after surgery. These patients were to be discharged from the ICU in the following 24 hours, and were representative of patients who underwent surgical stress. Nineteen healthy volunteers, who did not have any chronic or acute illnesses, and were not on any medications, were selected among hospital workers and served as the control group. Samples of blood and saliva were collected at $8 \mathrm{AM}$, after an overnight fast. Patients with human immunodeficiency virus (HIV) infection, pituitary or adrenal diseases, those using corticosteroids or estrogen (in the previous year) or any other drug that could interfere with cortisol secretion, such as etomidate and ketoconazole (in the previous 6 months), were excluded from this study. We also excluded any patients with visible bleeding in the oral cavity.

\section{Laboratory analysis}

Serum samples for total cortisol and albumin determination were collected by venipuncture of the arms, that did not have any infusions. Simultaneously, saliva samples were obtained by placing in the mouth of the patient dental cotton rolls containing citric acid to stimulate the flow of saliva. Rolls were left in the mouth until cotton was completely saturated, but for no more than 20 minutes. Cotton rolls were then placed in the saliva-collecting devices (Salivette ${ }^{\circledR}-$ Sarstedt $^{\circledR}$, Australia) 
and centrifuged to obtain saliva samples, which were immediately frozen for later analysis. The final volume of saliva was determined after centrifugation.

Serum total cortisol was determined by competitive chemiluminescence immunoassay (Immulite ${ }^{\circledR}-$ DPC $^{\circledR}$; Los Angeles - CA, USA). Salivary cortisol concentrations were determined using a competitive enzyme immunoassay kit (DSL ${ }^{\circledR}$; TX- USA). Among commercially available methods, this is the one that requires the smallest sample volume $(25 \mu \mathrm{L})$. Serum albumin measurements were done in Vitros $^{\circledR}$ Fusion $^{\circledR}$ analyzer using a colorimetric bromocresol green assay (Johnson \& Johnson ${ }^{\circledR}$, USA). According to manufacturer, intra and inter-assay coefficients of variation were: $6.2 \%$ and $10.0 \%$ for serum cortisol; $4.8 \%$ and $7.2 \%$ for salivary cortisol; and $0.8 \%$ and $1.1 \%$ for serum albumin.

\section{Statistical analysis}

We used Minitab ${ }^{\circledR}$ for Windows ${ }^{\circledR}$ (version 13.2). Mann-Whitney and Kruskall-Wallis tests were used for non-parametric measurements. We used the $\mathrm{Z}$ test to compare proportions. A $5 \%$ confidence level was considered statistically significant.

\section{RESULTS}

Clinical data of the three groups of subjects are presented in table 1. Average volume of saliva collected from the individuals enrolled in the study was $400 \mu \mathrm{L}$. We were unable to collect sufficient saliva for testing in $8(30 \%)$ patients with severe sepsis, in $6(30 \%)$ postoperative patients, and 1 (5\%) control subject. Using the Mann-Whitney test, median salivary cortisol was $7.0 \mu \mathrm{g} / \mathrm{dL}$ in patients with severe sepsis, $2.7 \mu \mathrm{g} / \mathrm{dL}$ in postoperative patients and $0.5 \mu \mathrm{g} / \mathrm{dL}$ in the controls $(\mathrm{p}<0.05$; table 2 and Figure 1$)$. Median serum total cortisol was $26.5 \mu \mathrm{g} / \mathrm{dL}$ in patients with severe sepsis, $18.7 \mu \mathrm{g} / \mathrm{dL}$ in postoperative patients and $11.3 \mu \mathrm{g} / \mathrm{dL}$ in controls $(\mathrm{p}<0.01)$. In patients with severe sepsis, median salivary cortisol concentration was 14 times higher than that of healthy subjects, and 2.6 higher than in postoperative patients (Figure 1). In postoperative patients, salivary cortisol was 5.4 times higher than in controls. Serum total cortisol was higher in patients with severe sepsis than in controls and postoperative patients. However, this increment was much smaller (2.33 and 1.64 respectively).

Median serum albumin was $1.9 \mathrm{~g} / \mathrm{dL}$ in patients with severe sepsis, $2.6 \mathrm{~g} / \mathrm{dL}$ in postoperative patients, and $4.3 \mathrm{~g} / \mathrm{dL}$ in the control group $(\mathrm{p}<0.01)$. Mortality stratified by class of salivary cortisol (A-D) is presented in table 3. Patients with salivary cortisol greater than $7.2 \mu \mathrm{g} / \mathrm{dL}$ had a mortality of $80 \%$, and this was statistically significant when compared with the group with lower levels $(\mathrm{Z}=2.38$ and $\mathrm{p}<0.05)$.

Table 1. Clinical data from the three groups studied

\begin{tabular}{|c|c|c|c|}
\hline Characteristic & SS & PO & $\mathbf{N}$ \\
\hline $\begin{array}{l}\text { n (Loss due to insufficient saliva } \\
\text { volume) }\end{array}$ & $27(8)$ & $20(6)$ & $19(1)$ \\
\hline Age (years) & $57.7 \pm 14.2$ & $60.4 \pm 12.8$ & $40.1 \pm 10.3^{*}$ \\
\hline \multicolumn{4}{|l|}{ Gender } \\
\hline Male & $15(55 \%)$ & $9(45 \%)$ & $5(25 \%)$ \\
\hline Female & $14(45 \%)$ & $11(55 \%)$ & $15(75 \%)$ \\
\hline \multicolumn{4}{|l|}{ Site of infection } \\
\hline Abdomen & $12(44 \%)$ & - & - \\
\hline Chest & $10(37 \%)$ & - & - \\
\hline Urinary tract & $3(11 \%)$ & - & - \\
\hline Skin & $2(7 \%)$ & - & - \\
\hline \multicolumn{4}{|l|}{ Supportive therapy } \\
\hline Vasoactive drugs & $25(93 \%)$ & - & - \\
\hline Mechanical ventilation & $21(78 \%)$ & - & - \\
\hline Dialysis & $3(11 \%)$ & - & - \\
\hline Corticosteroid use & $10(37 \%)$ & - & - \\
\hline Mortality & $15(56 \%)$ & - & - \\
\hline \multicolumn{4}{|l|}{ Site of surgery } \\
\hline Cardiovascular & - & $7(35 \%)$ & - \\
\hline Genitourinary & - & $4(20 \%)$ & - \\
\hline Gastrointestinal & - & $3(15 \%)$ & - \\
\hline Peripheral vascular system & - & $2(10 \%)$ & - \\
\hline Gynecological & - & $2(10 \%)$ & - \\
\hline Neurological & - & $2(10 \%)$ & - \\
\hline
\end{tabular}

SS: patients with severe sepsis; PO: postoperative patients; N: normal. ${ }^{*} p<0.05$.

Table 2. Laboratory results of the groups analyzed

\begin{tabular}{lccc}
\hline & SS & PO & N \\
\hline Salivary Cortisol $(\mu \mathrm{g} / \mathrm{dL})$ & & & \\
Mean + SD & $11.90 \pm 17.00$ & $2.18 \pm 1.46$ & $1.00 \pm 0.87$ \\
Median & $7.00^{\star}$ & $2.71^{\star}$ & $0.50^{\star}$ \\
Min-Max & $1.20-63.30$ & $0.30-4.83$ & $0.30-3.20$ \\
Serum Cortisol $(\mu \mathrm{g} / \mathrm{dL})$ & & & \\
Mean + SD & $39.20 \pm 34.80$ & $19.44 \pm 6.4$ & $13.02 \pm 4.95$ \\
Median & $26.50^{\star}$ & $18.70^{\star}$ & $11.35^{\star}$ \\
Min-Max & $11.80-142.00$ & $10.70-33.80$ & $5.70-22.50$ \\
Serum Albumin $(\mathrm{g} / \mathrm{dL})$ & & & \\
Mean + SD & $1.90 \pm 0.43$ & $2.64 \pm 0.69$ & $4.24 \pm 0.23$ \\
Median & $1.9^{\star}$ & $2.60^{\star}$ & $4.30^{\star}$ \\
Min-Max & $1.30-3.10$ & $1.70-4.30$ & $3.90-4.60$ \\
\hline
\end{tabular}

SS: patients with Severe Sepsis; PO: postoperative patients; $N$ : normal. ${ }^{*} p<0.05$. 

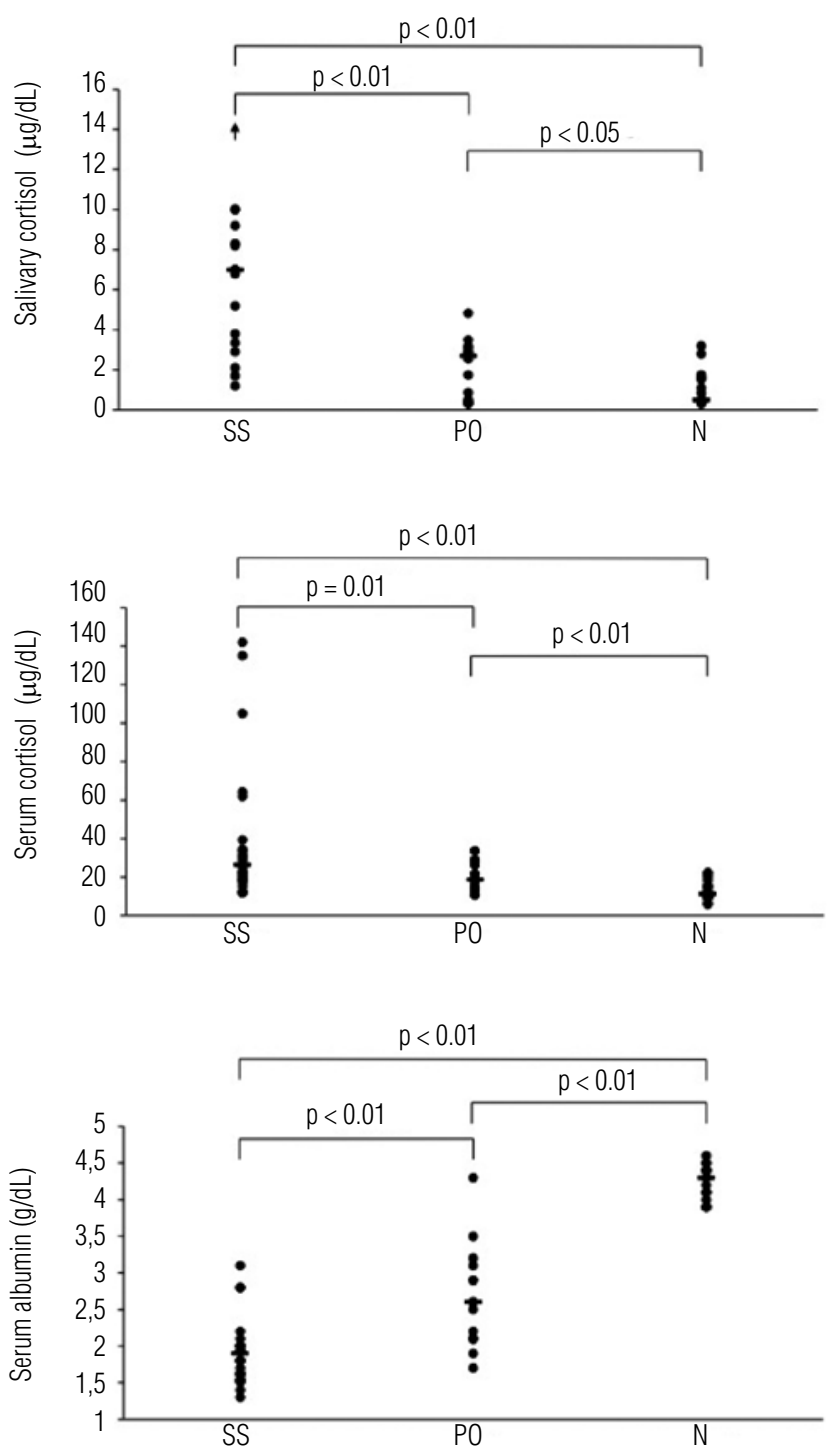

Figure 1. Serum, salivary cortisol and albumin measurement in severe sepsis (SS) and postoperative (PO) patients, and in healthy controls (N).

Table 3. Mortality index stratified by class of salivary cortisol

\begin{tabular}{lcccc}
\hline Class & Salivary cortisol & $\mathbf{n}$ & Deaths & $\%$ \\
\hline $\mathrm{A}$ & $<5.0 \mu \mathrm{g} / \mathrm{dL}$ & 5 & 1 & 20 \\
$B$ & $5.0-7.2 \mu \mathrm{g} / \mathrm{dL}$ & 4 & 2 & 50 \\
$C$ & $7.2-14.5 \mu \mathrm{g} / \mathrm{dL}$ & 8 & 6 & $75^{*}$ \\
$D$ & $>14.5 \mu \mathrm{g} / \mathrm{dL}$ & 2 & 2 & $100^{\star}$ \\
\hline
\end{tabular}

* $p<0.05$

\section{DISCUSSION}

There has recently been a great deal of interest regarding the assessment of adrenal function in critically ill patients. Approximately $90 \%-93 \%$ of cortisol in the circulation is bound to transcortin and albumin, with the remaining $7 \%-10 \%$ being the free biologically active fraction. Commercially available cortisol assays measure total, rather than free cortisol concentration. In critically ill patients, cortisol binding proteins fall on average by $50 \%(11,12)$. As demonstrated in our study, the degree of hypoproteinemia is more frequent and severe in patients with severe sepsis. Furthermore, the accuracy of commercially available methods that measure serum total cortisol vary, especially in patients with severe sepsis. Consequently, free, rather than serum total cortisol, is considered a more reliable method to assess adrenal function in critically ill patients (13).

It has been demonstrated that salivary cortisol can be used instead of serum total cortisol, since it represents the biologically active, free fraction of cortisol (20). In our study, we used salivary cortisol as an alternative to serum free cortisol.

Our data shows that, in patients with severe sepsis, median salivary cortisol concentration was 14 times higher than that of healthy subjects, and 2.6 higher than that of postoperative patients (Figure 1). Furthermore, salivary cortisol was 5.4 times higher in postoperative patients compared with controls. These findings suggest that the increase in salivary cortisol was proportional to the severity of the stress. Although serum total cortisol was higher in the patients with severe sepsis than in controls and postoperative patients, this increment was much lower $(2.3$ and 1.6 respectively; Table 1 and Figure 1). This is presumably a consequence of severe hypoproteinemia in our patients with sepsis, with an increase in the serum cortisol concentration above the saturation point of transcortin (20).

The number of patients investigated is a limitation of our study and could explain the overlap of cortisol levels in severe sepsis and postoperative patients, although the difference was statisticall significant. The relatively high ICU mortality of our patients with severe sepsis $(56 \%)$ was attributed to the severity to their illness $(93 \%$ used vasoconstrictors and 78\%, mechanical ventilation). Salivary cortisol was much higher $(\mathrm{p}<$ $0.05)$ in the group of patients who died. Comparison using the $\mathrm{Z}$ test demonstrated a mortality of $80 \%$ in patients with a salivary cortisol greater than $7.2 \mu \mathrm{g} / \mathrm{dL}$ (Table 2), and this finding was statistically significant when compared with the group with lower salivary cortisol levels $(Z=2.38$ and $p<0.05)$. Since we do not have the interference of low protein levels in this assay, salivary cortisol may reflect the severity of the patient's conditions more realistically. 
Although hydrocortisone treatment outcome was not in the scope of this study, we did not find differences in mortality when we compared patients who received treatment with hydrocortisone as opposed to those who were not treated. The criterion used to treat the patients with hydrocortisone was the need for vasopressor drugs 12-24 hours after volume resuscitation.

To our knowledge, there is only one recently published paper demonstrating the use of salivary cortisol in critically ill patients (13). These investigators demonstrated that salivary cortisol concentrations correlated well with measured serum free cortisol levels and provided an indirect, yet reliable and practical, assessment of serum free cortisol concentration during critical illness (13).

The most important limitation of salivary cortisol measurement is the difficulty in collecting the samples in intubated and dehydrated patients, as shown in a previous study (15). This problem may be overcome by collecting the samples after volume resuscitation. In our study it was not possible to analyze 30\% of the samples from the original severe sepsis and postoperative groups due to the small volume collected.

In conclusion, we have demonstrated that the collection of saliva samples is feasible in the majority of critically ill patients, and that commercially available assay kits are cheap and easy to use in the clinical setting. The increase in salivary cortisol is more reliable than serum total cortisol in the diagnosis of CIRCI. Furthermore, this is the first study to demonstrate a relationship between salivary cortisol and mortality rate. Additional studies are required to determine the role of salivary cortisol in establishing the diagnosis and prognosis of CIRCI in critically ill patients. Our data supports the body of literature demonstrating the limitations of serum total cortisol determination in the diagnosis of CIRCI.

Acknowlegments: Prof. Airton Moreira, Ms. Laudislene and Mr. Carlos Barros, from Medlab.

Disclosure: no potential conflict of interest relevant to this article was reported.

\section{REFERENCES}

1. Annane D, Maxime V, Ibraim F, Alvarez JC, Abe E, Boudou P. Diagnosis of adrenal insufficiency in severe sepsis and septic shock. Am J Repir Crit Care Med. 2006;174(12):1319-26.
2. Marik PE, Pastores SM, Annane D, Meduri GU, Sprung CL, Arlt W, et al. Recommendations for the diagnosis and management of corticosteroid insufficiency in critically ill adult patients: consensus statements from an international task force by the American College of Critical Care Medicine. Crit Care Med. 2008;36(6):1937-49.

3. Marik PE. Critical illness-related corticosteroid insufficiency. Chest. 2009;135:181-93.

4. Rivers EP, Gaspari M, Saad GA, Mlynarek M, Fath J, Horst HM, et al. Adrenal insufficiency in high-risk surgical ICU patients. Chest. 2001;19(3):889-96.

5. Marik PE, Zaloga GP. Adrenal insufficiency in the critically III: A new look at an old problem. Chest. 2002;122:1784-96.

6. Annane D, Sebille V, Charpentier C, Bollaert PE, François B, Korach JM, et al. Effect of treatment with low doses of hydrocortisone and fludrocortisone on mortality in patients with septic shock. JAMA. 2002;288:862-71.

7. Marik PE, Gayowski T, Starzl TE. The hepatoadrenal syndrome: a common yet unrecognized clinical condition. Crit Care Med. 2005;33:1254-59.

8. Annane D, Maxime V, Ibrahim F, Alvarez JC, Abe E, Boudou P, et al. Diagnosis of adrenal insufficiency in severe sepsis and septic shock. Am J Respir Crit Care Med. 2006;174(12):1319-26.

9. Oppert M, Schindler R, Husung C, Offermann K, Gräf KJ, Boenisch $\mathrm{O}$, et al. Low-dose hydrocortisone improves shock reversal and reduces cytokine levels in early hyperdynamic septic shock. Crit Care Med. 2005;33(11):2457-64.

10. Bollaert PE, Charpentier C, Levy B, Debouverie M, Audibert G, Larcan A. Reversal of late septic shock with supraphysiologic doses of hydrocortisone. Crit Care Med. 1998(4);26:645-50.

11. Hamrahian AH, OseniTS, Arafah BM. Measurement of serum free cortisol in critically ill patients. N Eng J Med. 2004;350:1629-38.

12. Ho JT, Al-Musalhi H, Chapman MJ, Quach T, Thomas PD, Bagley $\mathrm{CJ}$, et al. Septic shock a sepsis: a comparison of total and free plasma cortisol levels. J Clin End Metabol. 2006;91:105-14.

13. Arafah BM, Nishiyama FJ, Tlaygeh H, Hejal R. measurement of salivary cortisol concentration in the assessment of adrenal function in critically ill subjects: a surrogate marker of the circulating free cortisol. J Clin Endocrinol Metab. 2007;92(3):2965-71.

14. Dimopoulou I, Alevizopoulou P, Dafni U, Orfanos S, Livaditi O, Tzanela $\mathrm{M}$, et al. Pituitary adrenal response to human corticotrophin releasing hormone in critically ill patients. Intensive Care Med. 2007;33(3):454-9.

15. Cohen J, Venkatesh B, Galligan J,Thomas P. Salivary cortisol concentration in the intensive care population: correlation with plasma cortisol values. Anaesth Inten Care. 2004;32:843-5.

16. Martinelli CE Jr, Sader SL, Oliveira EB, Daneluzzi JC, Moreira AC. Salivary cortisol for screening of Cushing's syndrome in children. Clin Endocrinol. 1999;51(1):67-71.

17. Castro M, Elias LLK, Elias PCL, Moreira AC. A dose-response study of salivary cortisol after dexamethasone suppression test in Cushing's disease and its potential use in the differential diagnosis of Cushing syndrome. Clin Endocrinol. 2003;59(6):800-5.

18. Castro M, Moreira AC. Análise crítica do cortisol salivar na avaliação do eixo hipotálamo-hipófise-adrenal. Arq Bras Endocrinol Metab. 2003;47(1):358-67.

19. Levy MM, Fink MP, Marshall JC, Abraham E, Angus D, Cook D, et al. $2001 \mathrm{SCCM} / \mathrm{ESICM} / \mathrm{ACCP} / \mathrm{ATS} / \mathrm{SIS}$ International Sepsis Definitions Conference. Crit Care Med. 2003;31(4):1250-6.

20. Gozansky WS, Lynn JS, Laudenslager ML, Kohrt WM. Salivary cortisol determined by enzyme immunoassay is preferable to serum total cortisol for assessment of dynamic hypothalamic-pituitary-adrenal axis activity. Clin Endocrinol. 2005;63(3):336-41. 